\title{
The prevalence and distribution of bruising in babies
}

\author{
R F Carpenter
}

\begin{abstract}
Aim-To obtain a prevalence rate and determine the distribution of accidental bruising in babies.

Methods-177 babies aged 6-12 months were examined naked to look for bruises. They were seen in health visitor hearing test clinics and child health surveillance clinics. The site, size, shape, and colour of bruises were recorded on a skin map, and the parent's explanation noted. Any other injury was recorded. Data collection included the baby's age, mobility and weight, demographic details, and health visitor concerns.

Results-Twenty two babies had bruises, giving a prevalence rate of $12 \%$. There was a total of 32 bruises, 15 babies had one bruise. All bruises were found on the front of the body and were located over bony prominences. Twenty five of the bruises were on the face and head, and seven were on the shin. The babies with bruises on the shin were mobile. There was a highly significant increase in bruises with increase in mobility.

Conclusions-The study has produced a prevalence and distribution of bruising in babies and sets a baseline from which to work when assessing bruises. It also tested out the methodology, which could be used in further research, particularly of younger babies. Clinicians need to assess a baby's level of development when considering whether a bruise is accidental. (Arch Dis Child 1999;80:363-366)
\end{abstract}

Keywords: bruising; child abuse; accidental injury

When a child is seen with bruising it is a medical responsibility to determine whether these injuries are consistent with the history and the child's age, development, and level of activity. ${ }^{1}$ If they are not, child protection issues must be considered. $^{23}$ The expertise and confidence of doctors to assess injuries in children depends on experience and the evidence obtained from informed studies about injuries sustained accidentally or non-accidentally. There is a lack of information about accidental bruising in children, particularly in babies. Less research has been devoted to soft tissue injuries than to fractures and head injuries, ${ }^{4-7}$ yet the skin can show the commonest and most easily recognised manifestations of abuse in children. ${ }^{8}$

Patterns and sites of bruising in children that are suggestive of abuse have been well documented. ${ }^{4}{ }^{10}$ Bruises found in "soft" sites, such as cheeks or trunk, suggest abuse. ${ }^{11}$ In contrast, there is little written about accidental bruising in children, particularly in terms of the average number of bruises on a child at any one time. In a general review of bruising in children, Stephenson stated that it is hard to find data on absolute numbers of bruises in accidentally injured children. ${ }^{10}$ Hobbs suggested that as many as 12 bruises may be seen in non-abused children. ${ }^{12}$

Pascoe $^{11}$ and Roberton ${ }^{9}$ looked at injuries, accidental and non-accidental, in children and compared their patterns and distribution. In both studies, the numbers of bruises in babies were too small to make a comparison or to comment on distribution. In children over 1 year old, accidental bruises tended to be found over bony prominences. Only Roberton gives a prevalence rate for bruising in babies $(12.5 \%)$, using a small sample of 62 babies aged 3-9 months.

One of the cardinal signs of abuse is a discrepancy between the physical finding and the history. Hobbs summarised studies which stated that injuries sustained after falling from a bed, sofa, or similar height tend to be minor. ${ }^{12}$ Thus, for children presenting with severe injuries and a history of a fall from a chair, bed, or cot, non-accidental injury should be considered. Similarly, children falling down a flight of stairs frequently injure themselves, but not seriously. $^{13}$

It is sometimes difficult to distinguish accidental injury from abuse or to distinguish abuse from diseases and other conditions that produce similar signs. ${ }^{14}{ }^{15}$ Such conditions include bleeding disorders ${ }^{16}$; connective tissue disorders ${ }^{10}{ }^{15}$; dye, paint, and pen marks ${ }^{10}$; folk remedies $^{17}{ }^{18}$; phytophotodermatitis ${ }^{19}$; Mongolian blue spots $^{14{ }^{152}}$; and cafe au lait spots. ${ }^{10}$ Therefore, errors in diagnosis can occur ${ }^{14}$ and a mistaken diagnosis of abuse can be devastating for a family.

Babies up to about 9 months are not as independently mobile or active and so few bruises are expected. It could be assumed that any bruises in this age group are indicative of abuse. My study aimed to determine a prevalence and distribution of bruising seen in babies, to enable bruising in this age group to be assessed more accurately and confidently.

\section{Methods}

My study was carried out between July 1996 and April 1997. It was started in the area around Burnley, East Lancashire, and completed in Darlington, County Durham. Ethical approval was obtained. 


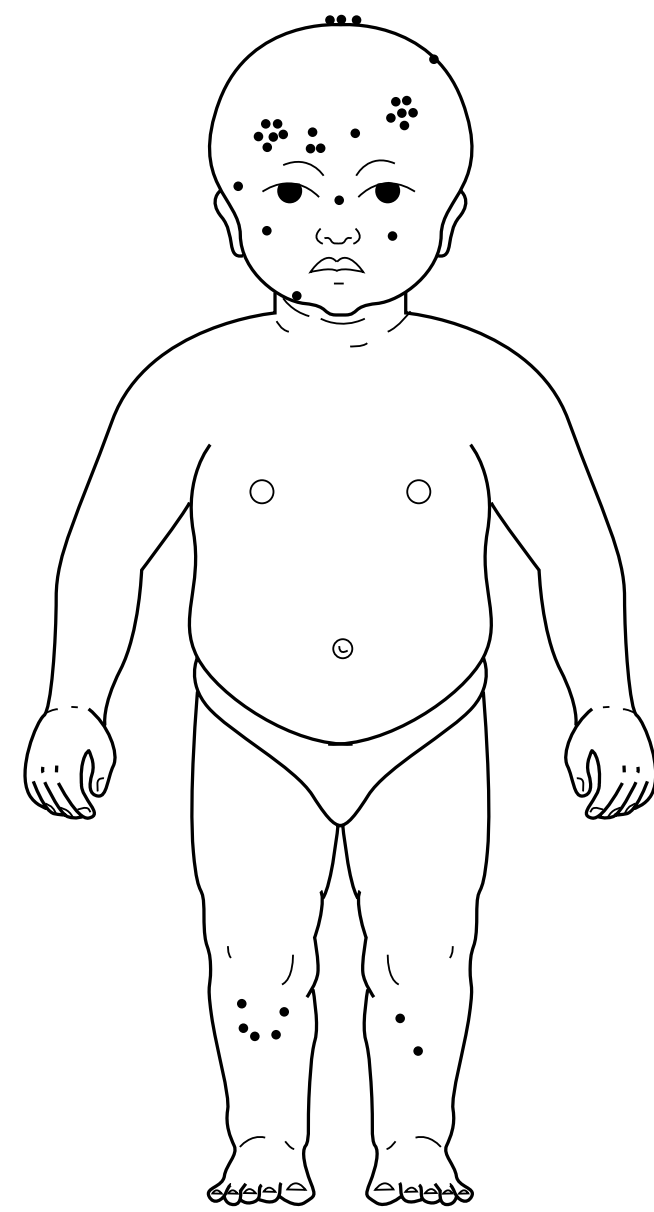

Figure 1 Illustration of the approximate sites of all the observed bruises.

Using the only other prevalence rate for bruising in babies $\left(12.5 \%{ }^{9}\right)$, a sample size of 175 babies was calculated.

The babies were enrolled from the health visitor hearing test clinics and developmental checks of babies between the ages of 6 and 9 months, part of "child health promotion", which targets all children. ${ }^{21}$ The average uptake of the clinics attended was over $90 \%$. Different clinic locations were used in both districts to ensure full demographic coverage.

Each baby had a full examination of the skin, naked. Parents were told about the study, asked to participate and given an explanatory leaflet before being seen.

One pro forma was used to record all the information collected, and covered basic details of the baby, data to reflect the socioeconomic status, ethnic group, family structure, and the baby's mobility and growth. The clinical findings recorded included any pronounced skin rash, disease, or birth mark; and all injuries such as bruises, scars, or scratches. Bruises were measured with a plastic ruler. The injuries were also drawn on a skin map that had a superimposed colour chart. Site, size, and colour were recorded for each bruise and an explanation sought for each injury. Relevant health visitor concerns were noted. The same data were collected for any refuser and included health visitor concerns.
The data produced prevalence figures. The $\chi^{2}$ test was used to analyse the data further (and Pearson's correlation in one instance).

No extra resources were required for the study.

\section{Results}

I approached the parents or carers of 178 babies. There was one refusal, with a valid explanation, and there were no concerns about this baby. Of 177 babies, 84 were boys and 93 were girls. The age range was 25.3-52 weeks (mean, 36.1; SD, 4.9). Comparing distribution of social class in the sample group with that in England and Wales (source, 1991 census) revealed that the upper social classes were underrepresented and there were more unemployed parents in the sample group.

There were 11 boys and 11 girls with bruises. The overall prevalence was $12.4 \%$ (95\% confidence interval (CI), $7.19 \%$ to $16.66 \%)$. The prevalence in boys was $13.10 \%(95 \%$ CI, $8.02 \%$ to $18.18 \%$ ). The prevalence in girls was $11.83 \%$ (95\% CI, $6.97 \%$ to $16.69 \%$ ). There was no significant difference in prevalence between boys and girls ( $p>0.5)$.

There were a total of 32 bruises seen in 22 babies. Fifteen babies had one bruise and seven babies had more than one bruise (five had two, one had three, and one had four bruises). Figure 1 shows the sites of the bruises. Twenty five bruises were on the face and head. The remainder (seven) were on the shins. Sixteen of the bruises were found on the forehead. The four bruises on the skull were seen in the same girl, who at 10 months was pulling to stand and repeatedly banged her head on the underside of the dining room table.

In all cases the bruises were located over bony prominences and on the front of the body. No bruise exceeded $10 \mathrm{~mm}$ in any dimension. Nine bruises had a maximum dimension of 1-3 mm, 14 had a maximum size of $4-6 \mathrm{~mm}$, and nine of $7-10 \mathrm{~mm}$. Bruises were roughly circular or rectangular and where they were more linear tended to reflect bony prominences, such as the orbit or chin. The largest bruises were on the forehead in two children. One baby fell off a settee on to a hard surface and the other banged her head on a cot bar trying to pull herself up to stand, but fell in the process. Bruises appeared when babies fell on to hard surfaces and on to soft surfaces, such as a carpet.

Different colours were seen and could not be matched with the age of bruises, except yellow, which only appeared in bruises over 48 hours old.

There were explanations for 23 bruises, most while mobilising, and no explanation for nine. In no baby did I suspect abuse or doubt the explanation, when given.

Table 1 Mobility of babies with bruises

\begin{tabular}{lrc}
\hline Mobility & $n$ & With bruises (n) \\
\hline Sits & 101 & 4 \\
Crawls & 52 & 9 \\
Walks & 24 & 9 \\
Total & 177 & 22 \\
\hline
\end{tabular}


Table 2 Other findings that could mimic abuse

\begin{tabular}{lrl}
\hline Finding & $n$ & Comment \\
\hline Haemangioma & 11 & One baby had 3 (total 13) \\
Pigmented naevus & 6 & One baby had 2 (total 7) \\
Cafe au lait & 5 & One baby had 3 (total 7) \\
Mongolian blue spot & 9 & One baby hd 3 discrete spots \\
Rash & 2 & One allergic, one "heat" rash \\
\hline
\end{tabular}

Table 1 shows the mobility of the 22 babies with bruises. There was a significant increase in bruises seen in babies with increase in mobility $(\mathrm{p}<0.001)$. All the babies with bruises on shins were mobile.

Eight of the bruised babies used baby walkers, and one injury was sustained while in the walker. Sixty babies in the sample group used baby walkers, a similar proportion. Therefore, bruised babies were no more likely to have used a walker $(\mathrm{p}>0.5)$. In babies who used a baby walker there were 12 bruises.

There was a positive correlation with a baby being bruised and increase in number of children in the family $(r=0.95)$. This was just significant at the $5 \%$ level ( $p>0.05)$.

Older babies appeared to have more bruises, and older parents seemed to have babies who were more likely to be bruised. However, for both, this was only just significant at the 5\% level $(p=0.05)$.

There was no significant difference between the parent's marital status or social class for prevalence of bruising ( $p>0.5$ for both), nor between the number of babies with bruises whose current weight was above and below the 9 th centile $(\mathrm{p}>0.5)$.

Fifteen babies had other injuries, all minor, comprising mainly scratches, a few abrasions, and one laceration. All except that on the sole of the foot were on the front of the body.

Table 2 shows the numbers of babies with other clinical findings that could mimic abuse.

\section{Discussion}

My study was designed to identify accidental bruising in babies. It is difficult to be certain that every bruise seen was accidental, even a small single bruise could be inflicted. My assumptions were based on the injury observed, the explanation given, the developmental level, growth and general care of the baby, the demeanour or behaviour of the baby and the parent, and the available knowledge about the whole family.

Most of the previous studies on children bruised accidentally have looked at children attending hospital and Roberton's sample was from an inner city area. ${ }^{9}$ None was necessarily representative of the general population. No study concentrated only on babies. My study aimed for a sample that represents the whole normal population of babies and which could give significant results.

The $90 \%$ uptake at the clinics ensured a good representative sample of the local population. However, if the non-attenders (under $10 \%$ ) had different characteristics this might have biased the results. It could be argued that those parents who had bruised their children would not bring them to clinic. But the aim of my study was to establish what is seen normally in terms of bruising, so non-accidental injury would not be included in the figures. It could also be argued that non-attenders are the ones more likely to have bruises, for several reasons. Accidents, which include those in the home, show a notable social gradient, ${ }^{2122}$ so more occur in babies from disadvantaged homes. Poor families tend to make less use of preventive services, such as child health surveillance, ${ }^{22}$ and access to services can also be difficult.

The proportion of infants on the Child Protection Register in my study was $1.1 \%$ (two babies), which is rather higher than the estimated figure for England and Wales (3-5/ 1000). In six more babies there were health visiting concerns. This suggests that some babies who were at greater risk of injury were being brought to the clinics.

An important part of the history is whether the explanation is compatible with the injury seen. When accidental injuries occur the history is often vivid, whereas in abuse it may be vague and can vary with each telling. In my study, the parents generally remembered the cause of the large bruises on their babies. Even when a child did fall off a chair or a stair the injury seen was still small. Some babies had an unexplained injury, which can be an indicator of abuse. However, all the parents handled and behaved appropriately with their babies, who were happy and sociable and there were no health visitor concerns. Nor were parents unnerved when asked about the bruises.

Not one of the small number of bruised babies had fallen out of bed. Most babies slept in a cot. Given the evidence from this and other studies, ${ }^{12324}$ the practitioner should be very cautious about a parent who presents with a baby with one or more large bruises who is reported to have fallen out of bed.

The site of the bruising seen is very important. My findings agree with those of Roberton that most accidental bruising is over bony prominences. ${ }^{9}$ In addition, accidental bruises tend to be on the front of the body in this age group. Bruises on the shin occur in mobile babies.

In summary, my study has produced a prevalence for bruising in babies (12.4\%), a similar figure to that of $12.5 \%$ produced by Roberton. ${ }^{9}$ It also described the pattern and distribution of bruises seen, and found a highly significant increase in number of bruises with increased mobility. It has proved that the methodology devised is an effective way of collecting relevant data for bruising in babies.

I thank Dr SE Wyatt (University of Leeds) in particular; and the health visitors in Burnley and Darlington, Dr JM Wynne, Dr CJ Hobbs, Dr D Thistlethwaite, and Dr PM Jones.

1 Schmitt BD. Current pediatric roles in child abuse and neglect. Am f Dis Child 1979;133:691-6.

2 Child protection: medical responsibilities. Addendum to "Working together-under the Children Act 1989". Department of Health, British Medical Association, Conference of Medical Royal Colleges.

3 Working together-under the Children Act 1989. A Guide to arrangements for inter-agency co-operation for the proto arrangements for inter-agency co-operation for the p

4 Hobbs CJ, Hanks HGI, Wynne JM. Child abuse and neglect-a clinician's handbook. Edinburgh: Churchill Livingstone, 1994. 
5 Singleton EB. Intentional and unintentional abuse of infants and children. Curr Probl Diagn Radiol 1986;15:277-330.

6 Speight, N. ABC of child abuse. Non-accidental injury. BMF 1989;298:879-81.

7 Worlock P, Stower M, Barbor P. Patterns of fractures in accidental and non-accidental injury in children: a comparative study. BMF 1986;293:100-2.

8 Ellerstein NS. The cutaneous manifestations of child abuse and neglect. Am F Dis Child 1978;133:906-9.

9 Roberton DM, Barbor P, Hull D. Unusual injury? Recent injury in normal children and children with suspected nonaccidental injury. BMF (Clin Res Ed) 1982;285:1399-401

10 Stephenson T. Bruising in children. Current Paediatrics 1995;5:225-9

11 Pascoe JM, Hildebrandt MD, Tarrier A, et al. Patterns of skin injury in nonaccidental and accidental injury. Pediatrics 1979;64:245-7.

12 Hobbs C. Could it have happened when he fell, doctor? Child Abuse Review 1994;3:148-50.

13 Joffe M, Ludwig S. Stairway injuries in children. Pediatrics 1988;82:457-61.

14 Wheeler D, Hobbs C. Mistakes in diagnosing nonaccidental injury: 10 years experience. BMF 1988;296: $1233-6$.
15 Wardinsky TD. Genetic and congenital defect condition that mimic child abuse. F Fam Pract 1995;41;4:377-83.

16 O'Hare AE, Eden OB. Bleeding disorders and nonaccidental injury. Arch Dis Child 1994;59:860-4 .

17 Asnes RA, Wisotsky DH. Cupping lesions simulating child abuse. F Pediatr 1981;99:267-8.

18 Yeatman GW, Shaw C, Barlow MJ, et al. Pseudobattering in Vietnamese children. Pediatrics 1976;58:616-18.

19 Barradell R, Addo, A, McDonagh AJG, et al. Phytophotodermatitis mimicking child abuse. Eur F Pediatr 1993;152: 291-2.

20 Asnes RA. Buttock bruises = Mongolian spot. Pediatrics 1984;74:321.

21 Hall DMB. Health for all children, 3rd ed. Oxford: Oxford University Press, 1996.

22 Spencer N. Poverty and child health. Oxford: Radcliffe Medical Press, 1996.

23 Helfer RE, Slovis TL, Black M. Injuries resulting when small children fall out of bed. Pediatrics 1977;60:533-5.

24 Nimityongskul MD, Anderson LD. The likelihood of injuries when children fall out of bed. $\mathcal{F}$ Pediatr Orthop $1987 ; 7: 184-6$. 